\title{
Supporting College Students with Disorder of Written Expression: A Web-Based Model for Teachers in Under- Resourced Contexts
}

\author{
https://doi.org/10.3991/ijet.v15i11.12767 \\ Ani Zhang \\ Xinjiang Teacher's College, Xinjiang, China \\ Xiaodong Zhang $(\bowtie)$ \\ Beijing Foreign Studies University, Beijing, China \\ zxdman588@gmail.com
}

\begin{abstract}
In many under-resourced contexts, college teachers who have students with special needs are often insufficiently supported due to external constraints, such as limited teacher training or geographical constraints. To promote educational equity as well as college teachers' development in underresourced contexts, this paper provides a model that highlights the role of college teachers' self-directed development in relation to the use of web resources as knowledge suppliers. In particular, with disorder of written expression in English as the focus, the study demonstrates how college English teachers gain a systematic and multi-layered understanding of writing as a meaning-based activity through their self-directed use of web resources to best help their students. This paper concludes with implications in relation to the potential challenges of implementing the model at various levels in under-resourced contexts (e.g., the role of institutional assistance).
\end{abstract}

Keywords-Web resources, special education, under-resourced contexts, teacher empowerment, disorder of written expression

\section{$1 \quad$ Introduction}

While many countries have responded to the call for providing equitable education to college students with special needs, the way of assistance is not the same [1]. In some Western countries, a relatively mature system has been established, especially in the form of inclusive education [1]. Although its definition is still controversial, the basic tenets of inclusive education are exemplified by students' learning in the same classroom regardless of their background (e.g., those with or without special needs) [2]. In these contexts, other assistance also works in parallel, providing necessary help to students with learning challenges, such as psychological assistance or even individualized assistance [1]. Through such collaborative efforts between the teachers and off-class help, students with special needs are effectively supported [1]. In comparison, assistance to the students with special needs is developing but restricted in under- 
resourced contexts by diverse factors, such as financial investment, teachers' pre- or in-service training, and geographical factors [3], [4]. For example, in some regions of China, students of special needs have been given sufficient attention and also opportunities to study in the general education classroom. However, due to a lack of additional after-school assistance, these students are only attended by the general education teachers, who lack expertise in special education [2].

Nevertheless, to mitigate the issues in under-resourced contexts, teachers could initiate their own self-directed development in relation to their students with special needs [3]. Fortunately, the Internet has made knowledge dissemination accessible and almost free to everyone [5]. In other words, the use of web resources can be a useful channel through which teachers can update their knowledge to benefit their students [5]. Take disorder of written expression in English (DWEE), for example. Except for other areas of writing difficulties (e.g., handwriting difficulty), one feature of DWEE is related to college students' failure to demonstrate meaningful writing [6]. This means that it is important for college teachers to grasp English writing as a meaningbased literacy activity and help students with DWEE unpack it in an accessible way [7]. However, in under-resourced contexts, the synergy between teachers' selfdirected development and the use of web resources to help students with DWEE is still lacking. To this end, this paper attempts to offer an interrelated framework revolving around two foci: (1) the synergized potential of teacher education for college English writing teachers and web-based resources from a self-directed perspective with a focus on DWEE; and (2) recommended web resources that help college English teachers in under-resourced contexts address concerns surrounding students with DWEE.

\section{Self-Directed Development for Teachers in Relation to Students with Special Needs}

In under-resourced contexts, one way for teachers to develop is through selfdirected development [3], whereby teachers take their own initiative. They spur themselves on, counteracting the limitations of external assistance within the context by drawing on effective pedagogical knowledge and addressing their own classroom needs [8], [9]. It takes the form of an iterative cycle, which includes teachers' reflections, action taking, and evaluation until satisfactory results are achieved [9]. For college classrooms with students with DWEE, this means that college writing teachers need to take the initiative to understand their students' learning issues, discarding lecture-based teaching in spite of external contexts. Instead, teachers should take a student-centered approach, motivating themselves to delve into students' real learning issues. As a result of this process, the teacher may well notice the issues facing students with DWEE and contrive ways to help them. For example, based on issues identified in the classroom, such as a lack of explicit techniques for students with DWEE to construct writing meaningfully, teachers may convey techniques that could be compatible with the students' needs. Following assessments of the learning outcomes of students with DWEE, teachers may continue their new round of self-directed de- 
velopment [3]. The power of teachers' activation of self-agency and its application to their teaching has been illustrated in the field of special education, such as [3], [4], although not particularly in relation to students of DWEE. In all, promoting selfdirected development is a way of steering teachers away from their reliance on external assistance, especially for those who have students with special needs in underresourced contexts and where external assistance is limited.

In the process, teachers' knowledge of the subject is the core, as it is in reference to this knowledge that teachers make reflections or curricular changes when continuing their self-directed development [10]. In other words, utilizing or updating pedagogical knowledge is a core step to the success of self-directed development. It is fortunate that assimilating the knowledge in this digitalized world is not difficult as web resources provide a wide range of information for teachers to draw on and update their knowledge [5].

\section{Web-Based Resources as Knowledge Suppliers}

Web resources are suitable for updating teachers' knowledge in under-resourced contexts. Indeed, these online resources are free or nearly free and can be accessed without geographical constraints, making them optimal resources for teachers in under-resourced contexts [11]. These web resources include diverse forms supported by technological affordances, such as audio-visual resources, online texts, and massive open resources [12]. In addition, the web resources exemplify their value through their continual updating, offering diverse aspects of knowledge [11]. This makes the use of web-based resources potentially helpful to teachers who have students with special needs. Indeed, special education is complex with changing needs from the students; this makes professional development an on-going process and calls for teachers to constantly update their knowledge [4]. In classrooms where students with special needs are included, it is common for teachers to lack critical knowledge to understand their classroom issues, although they may try to help students with learning disabilities [3]. To effectively promote equitable education, teachers in these settings need to prepare themselves to assimilate crucial knowledge that could be found online [4], [5]. Taken together, because of the convenience of web resources and their wide range of information, they are optimal resources for teachers' self-directed development.

For college students with DWEE, teachers in under-resourced contexts need to gain knowledge of writing mechanisms online, which could effectively connect language resources with meaning construction [13]. This is because writing is a process of using language resources to construct meaning [14]. While there might be many other options available, scholars have argued that teachers' learning of systemic functional linguistics (SFL) is a good approach (as discussed in Section 4 below), because it can "account for the phenomenon [language disorder] observed in an integrated model that connects the different strata of language" [7, p.142]. In other words, SFL emphasizes meaning but also provides transparent layers of linguistic knowledge that help understand meaning construction [15]. Indeed, SFL, as a teaching praxis, has 
been well documented in promoting language-related equitable education for language learners [14], although research in DWEE is still weak. This may be related to a lack of promotion among special educators [16]. In all, for teachers' self-directed development, assimilating SFL through web resources seems feasible for those who have students with DWEE.

Notably, while self-directed development involves a minimum of external resources, it still means a change of instructional content [4]. Unsurprisingly, it may upset administrators in a local context, as the test-related grade is still generally valued as a metric of a school's reputation in some contexts [2]. A balanced strategy for teachers would attend to students' test-related skills and the authentic benefits of students with special needs. SFL in the writing classroom is quite compatible with both the demands of test grades and the demands of students with special needs, because SFL-based teaching includes and goes beyond what is expected on tests [14]. In other words, it is a good example for achieving balanced results in that it does not downplay language skills (as expected by tests); rather, it teaches more and explicitly shows how writing is made meaningful through language resources, as discussed in Section 4 below.

\section{$4 \quad$ Sourcing SFL-Based Knowledge Online: What Is It About?}

SFL, as a language theory derived from empirical data, clearly explicates written discourse as a meaning-based activity [14]. In explaining meaning construction, SFL has demonstrated its power and clarity on three levels [15]. One is to show the connection between writing and the external context [14]. That is, the text is meaningful because text construction takes place in an externally influenced context. In particular, the external context involves what is written about, who is written to, and how it is written [15]. In echoing the external context and its three constitutive elements, SFL also notes the corresponding meanings that represent the three contextual elements: ideational meaning (the events described in a text and their logical relationship), interpersonal meaning (attitude, stance or tone in relation to a text), and textual meaning (the fluency of a text) [15]. In other words, in showing the three meanings, SFL also clarifies the fuzziness of meaning configuration through the three dimensions of meaning. In further showing the mechanism of meaning, SFL provides a set of linguistic categories to understand the configuration of meanings. Rather than an attempt to show the exhaustive and once-for-all features of writing, SFL's linguistic labels provide a powerful and dynamic perspective to understand the constellation of linguistic features in different types of writing [17].

For example, linguistic codes include participants (coding nouns or noun phrases) and processes (coding verbs or verb phrases), aiming to show who or what is involved in the linguistic event when constructing ideational meaning. For instance, in narrative writing, SFL points out that pronouns and saying verbs, respectively corresponding to participants and processes, are often used in this type of writing [17]. Linguistic codes for the interpersonal meaning, such as modal verbs, predicates, and attitudinal resources (e.g., expressions indicating emotion or judgment), help understand mean- 
ing construction in different types of writing regarding information certainty, reliability, or trustworthiness as well as the text authors' or in-text figures' attitudes [17]. For example, SFL systematically shows how the information delivered to audiences varies at the linguistic level across contexts. When information is not certain, modal verbs or semantically weak verbs (e.g., suggest, indicate) are used. In addition, when information is to inform the audience of knowledge as in informational texts but not opinionated or argumentative texts, language carrying attitude has to be avoided (e.g., the overt use of adjectives) [17]. In explaining textual meaning, SFL also points out the use of cohesive devices in realizing this meaning in different types of writing [15]. For example, these cohesive devices can be found at the level of vocabulary (e.g., synonyms/antonyms/hyponyms across different sentences to form semantic relationships) and the level of grammar (e.g., conjunction words).

As shown above, SFL provides a transparent and convenient tool for understanding writing as a meaning-based activity. Teachers could learn SFL through web resources to best help students with DWEE in and out of class, since it well serves both general students and those with writing challenges.

\section{Teachers' Self-Directed Development Through Web-Based Resources: Practices and Tips}

This section provides a snippet of the self-directed process, based on the integration of web resources and SFL for college writing teachers in under-resourced contexts who have students with special needs. The first and foremost thing for teachers' self-directed development is their realization of the importance of improving themselves as well as their willingness to use technology as a new knowledge supplier [4] [10]. Without teachers' determination or motivation to help students with DWEE, they may not empower themselves to conduct or to continue self-directed development, as it is a long process that requires addressing students' individual needs and, thus, is taxing on teaching [3]. Therefore, prior to self-directed development, teachers should be encouraged to maintain their professional passion and embrace the use of non-traditional modes of knowledge delivery (i.e., web resources). Nevertheless, selfdirected development does not mean a hermetically individualized trajectory [3]. In the process of learning SFL, teachers could ask for help through web-based resources to overcome geographical constraints, such as discussion forums or online conferences.

Second, teachers may not have gained relevant knowledge on special education from their pre-service education, or the knowledge they gained is insufficient to manage their existing classroom [4]. For DWEE in general, teachers may need to enhance their understanding, in which online resources are readily available (see Table 1 below). For the knowledge input at the linguistic level, SFL resources can also be accessed online (see Table 1 below). In other words, the second step is for teachers to brainstorm, refresh, or update their knowledge of instructing writing among their students. In doing so, teachers can lay a foundation for their follow-up activities (e.g., analysis, reflection, and adaptation). Meanwhile, a tip for teachers' internationaliza- 
tion of their knowledge is not to overwhelm themselves with a researcher-like understanding. Instead, they could gain a good-enough understanding through diverse web resources [18]. These approachable materials are listed in Table 1.

Table 1. Teachers' self-directed development and sample link

\begin{tabular}{|l|l|}
\hline $\begin{array}{l}\text { Knowledge of DWEE in } \\
\text { general }\end{array}$ & $\begin{array}{l}\text { https://theaacn.org/wp-content/uploads/2015/10/aacn-ped-writing-ld-resouces- } \\
\text { K1 1-with-logo.pdf } \\
\text { https://www.edu.gov.mb.ca/k12/docs/support/learn disabilities/module4.pdf }\end{array}$ \\
\hline $\begin{array}{l}\text { Knowledge of SFL } \\
\text { ing) } \\
\text { https://www.annabellelukin.com/hallidays-textual-function.html (textual mean- } \\
\text { sonal meaning) } \\
\text { https://www.annabellelukin.com/hallidays-experiential-function.html (ideational } \\
\text { meaning) } \\
\text { https://www.annabellelukin.com/hallidays-logical-metafunction.html (ideational } \\
\text { meaning) } \\
\text { http://academics.smcvt.edu/CREATE/Lecture\%20Series\%20Documents/Schlep }\end{array}$ \\
$\begin{array}{l}\text { pegrell\%20and\%20Go,\%20Analyzing\%20Writing.pdf (using SFL to conduct } \\
\text { writing analysis and evaluation) }\end{array}$ \\
\hline $\begin{array}{l}\text { Knowledge of } \\
\text { instruction }\end{array}$ & $\begin{array}{l}\text { https://www.teachervision.com/special-needs/teaching-students-special-needs } \\
\text { https://www.washington.edu/teaching/topics/inclusive-teaching/teaching- }\end{array}$ \\
\hline $\begin{array}{l}\text { students-with-disabilities/ } \\
\text { https://www.eltresearchbites.com/201708-reading-to-learn-a-reading-and- } \\
\text { writing-pedagogy/ }\end{array}$ \\
\hline
\end{tabular}

The third step is to take action [4]. With the knowledge of SFL, teachers could try to analyze the writing issues of students with DWEE. For example, if students have issues with writing fluency, teachers could try to provide individualized after-class or in-class assistance to help them understand writing through teaching the relationship between the textual meaning and the explicit use of linguistic resources. Regarding the teaching, teachers need to take good care of the students in case of overwhelming them [3]. In addition to linguistic knowledge, other dimensions of knowledge are also necessary to best help students with DWEE, such as psychology or interactional skills [1], [4], as shown in Table 1. Faced with the problems in the instruction, teachers could diligently check relevant web resources to further update their knowledge or teaching strategies, according to the changing needs of students with DWEE [4], as shown in Table 1. It has to be mentioned again that while self-directed development highlights teachers' self-agency, moderate assistance can also be requested if necessary [3]. For example, help can be sought online from colleagues who are experts in the relevant fields.

The last step is evaluation [10], [19]. Following a certain trial period, teachers could evaluate their students' progress. Based on their work, teachers could conduct another round of self-directed development and make modifications by referring to web-based resources. For example, idea planning is a precursor to writing. If students with DWEE are troubled by this aspect along with language, teachers could think of other ways to help them, such as using group drama activities to help them construct ideas through multimodal and interactive ways [20]. In other words, evaluation can make self-directed development an iterative process, with students' interests always in the teachers' minds. 


\section{Conclusions and Implications}

In response to the limited resources in some contexts, this short paper showcases how in under-resourced contexts college writing teachers' self-directed development through web-based resources could help students with DWEE. For this area and other fields, several implications are worth attention by those who are interested in the framework. First, in some inclusive classrooms, students with special needs are often cared for by special educators. They may also need the knowledge of SFL to provide individualized assistance at the linguistic level [7]. Desirably, it is also recommended that these special educators initiate self-directed development in conjunction with web resources or general education teachers. Second, while reform policies on special education are constantly being implemented at the state or national level, the trajectory to realize these in a mature and localized manner to benefit some under-resourced schools could be slow [2]. However, reforms could first arise in local classrooms through web resources. When constellations of reforms are implemented through teachers' self-directed development, states or regions may notice the effect, and more efforts may be made on the part of administrations to highlight some practices as nationwide policies and promote them to the remaining areas. Third, in pre-service programs, teacher education could initiate courses on developing teachers' selfagency in relation to web resources [9]. In doing so, teacher educators could create simulated contexts or position pre-service teachers in real contexts to enable them to practice their efficacy in self-directed development and gain confidence in their future endeavors in more challenging or starkly different contexts. Similarly, in-service programs could also help teachers consolidate the role of self-agency in a similar way. Third, while self-agency is valued, discussions between colleagues are also encouraged [3]. Especially in this digitalized world, teachers in under-resourced contexts could share tips with each other on this self-reliant journey. This is also important because self-directed exploration could be emotionally draining; the collaborative space would also help relieve teachers' burdens [9]. This is particularly manifested among teachers who have students with special needs in their classrooms and have limited external support [1]. This is because their assistants may lack special education knowledge, and it is incumbent on them to develop knowledge on both the discipline subject and special education to cater to the diverse needs of the students in their classrooms [1]. Fourth, volunteer teaching is also valuable in under-resourced contexts [21]. In under-resourced areas, experts in special education could be encouraged to sojourn in these areas, providing assistance to college teachers during academic breaks. Such volunteer teachers could be placed on a regular basis between underresourced and developed areas where faculties are well supplied. Doing so may help mitigate local teachers' burdens, expediting their self-development process. Lastly, all the aforementioned is dynamically related to administration [3], [10]. It is hoped that administrators could afford teachers a scope of freedom to pursue instructional exploration on their own. 


\section{$7 \quad$ Acknowledgement}

This study is funded by National Social Science Foundation of China (17CYY019)

\section{References}

[1] B. J. Kritzer, "Comparing Special Education in the United States and China." International Journal of Special Education, vol. 27, no. 4, pp. 52-56, August, 2012.

[2] S. Q. Xu, P. Cooper, and K. Sin, "The 'Learning in Regular Classrooms' initiative for inclusive education in China," International Journal of Inclusive Education, vol. 22, no. 1, pp. 54-73, Jul. 2017. https://doi.org/10.1080/13603116.2017.1348547

[3] J. Shurr, M. Hirth, A. Jasper, M. McCollow, and J. Heroux, "Another Tool in the Belt: Self-Directed Professional Learning for Teachers of Students with Moderate and Severe Disabilities," Physical Disabilities: Education and Related Services, vol. 33, no. 1, pp. $17-$ 38, Jul. 2014. https://doi.org/10.14434/pders.v33i1.4855

[4] D. van Garderen, D. Hanuscin, C. N. Thomas, M. Stormont, and E. J. Lee, "Self-Directed Learning to Improve Science Content Knowledge for Teachers," Intervention in School and Clinic, vol. 52, no. 4, pp. 236-242, Jul. 2016. https://doi.org/10.1177/10534512166 $\underline{59476}$

[5] A. Jimoyiannis, P. Tsiotakis, D. Roussinos, and A. Siorenta, "Preparing teachers to integrate Web 2.0 in school practice: Toward a framework for Pedagogy 2.0," Australasian Journal of Educational Technology, vol. 29, no. 2, May 2013. https://doi.org/10.14742/ ajet. 157

[6] E. H. O'Donnell and M. K. Colvin, "Disorders of Written Expression," Current Clinical Psychiatry, pp. 59-78, Dec. 2018.

[7] E. Armstrong, "Language Disorder: A Functional Linguistic Perspective," Clinical Linguistics \& Phonetics, vol. 19, no. 3, pp. 137-153, Apr. 2005 https://doi.org/10.1080/ $\underline{02699200410001698599}$

[8] S.-H. Liu, "Factors Related to Pedagogical Beliefs of Teachers and Technology Integration," Computers \& Education, vol. 56, no. 4, pp. 1012-1022, May 2011. https://doi.org/ $\underline{10.1016 / j . c o m p e d u .2010 .12 .001}$

[9] M. van Wyk, "Exploring Student Teachers' Views on ePortfolios as an Empowering Tool to Enhance Self-Directed Learning in an Online Teacher Education Course," Australian Journal of Teacher Education, vol. 42, no. 6, pp. 1-21, Jun. 2017. https://doi.org/10.14 221/ajte.2017v42n6.1

[10] J. Richards and G. Skolits, "Sustaining Instructional Change: The Impact of Professional Development on Teacher Adoption of a New Instructional Strategy," Research in the Schools, vol. 16, no. 3, pp. 41-58, Fall. 2009.

[11] T. Caswell, S. Henson, M. Jensen, and D. Wiley, "Open Content and Open Educational Resources: Enabling Universal Education," The International Review of Research in Open and Distributed Learning, vol. 9, no. 1, Feb. 2008. https://doi.org/10.19173/irrodl.v9i1.469

[12] J. Olivier, "Short Instructional Videos as Multimodal Open Educational Resources in a Language Classroom," Journal of Educational Multimedia and Hypermedia, vol. 28, no.4, pp. 381-409, Oct. 2019

[13] X. Zhang, "Connecting OER With Mandatory Textbooks in an EFL Classroom: A Language Theory-Based Material Adoption," The International Review of Research in Open and Distributed Learning, vol. 19, no. 2, pp.89-110, May. 2018. https://doi.org/10.19173/ irrodl.v19i2.3479 
[14] M. Gebhard, I.-A. Chen, H. Graham, and W. Gunawan, "Teaching to Mean, Writing to Mean: SFL, L2 Literacy, and Teacher education," Journal of Second Language Writing, vol. 22, no. 2, pp. 107-124, Jun. 2013. https://doi.org/10.1016/j.jslw.2013.03.005

[15] S. Eggins, Introduction to Systemic Functional Linguistics. London: Continuum International Publishing Group, 2004.

[16] X. Zhang, "Diluting Minority Students' Marginalization in the Mainstream College English Writing Classroom Through Functional Linguistic Praxis: A Case Report from China," The Asia-Pacific Education Researcher, vol. 27, no. 6, pp. 465-475, Sep. 2018. https://doi. org/10.1007/s40299-018-0406-1

[17] M. J. Schleppegrell, The Language of Schooling: A Functional Linguistics Perspective. Mahwah, NJ: Lawrence Erlbaum, 2004.

[18] M. Macken-Horarik, "Why School English Needs a 'Good Enough' Grammatics (and Not More Grammar)," Changing English, vol. 19, no. 2, pp. 179-194, Jun. 2012. https://doi. org/10.1080/1358684x.2012.680760

[19] T. Cremin, K. Goouch, L. Blakemore, E. Goff, and R. Macdonald, "Connecting Drama and Writing: Seizing the Moment to Write," Research in Drama Education: The Journal of Applied Theatre and Performance, vol. 11, no. 3, pp. 273-291, Nov. 2006. https://doi. org/10.1080/13569780600900636

[20] H. Zhou and X. Shang, "Short-term Volunteer Teachers in Rural China: Challenges and Needs," Frontiers of Education in China, vol. 6, no. 4, pp. 571-601, Nov. 2011. https:// doi.org/10.1007/s11516-011-0146-y

\section{Authors}

Ani Zhang is an Associate professor at School of Educational Science, Xinjiang Teacher's College, China. Her research interests include special education, inclusive education and minority student education.

Xiaodong Zhang is an Associate Professor at School of English and International Studies, Beijing Foreign Studies University, China.

Article submitted 2019-12-15. Resubmitted 2020-02-21. Final acceptance 2020-02-21. Final version published as submitted by the authors. 